the strengths and weaknesses of university-industry collaborations that are in operation. Interaction with our own Associate Members is to be intensified. The national societies of EPS are urged to exert pressure in their own countries on governments, university authorities and industry to take action along the lines indicated and to treat the subject as both serious and urgent.

Copies of the full report are available, free of charge, on request from the EPS Secretariat in Geneva.

\section{Helping Developing Countries}

The International Centre for Theoretical Physics in Trieste has renewed its appeal for help in supplying libraries of universities in developing countries with back issues of journals and copies of physics books. Previous appeals have produced an encouraging response, but the need is great and continual. Little improvement is to be seen in the funding available for scientific information and frequently inflation and balance of payments' difficulties cause a deterioration in real terms so that the information deficit steadily rises even if a nucleus has, at one time, been established.

Colleagues in the more fortunate countries do not have illimited resources but they are, in the main, able to keep pace with current literature - if they can find somewhere to put it. Many physicists and libraries find their shelves packed with old journals and text books that they cannot bear to throw away, primarily, because they are still in good condition. These are what ICTP would like to direct towards the needy.

There is a similar market for redundant laboratory apparatus. Schools and universities accumulate equipment which has become obsolete because of changes in curricula, changes in teaching style, etc. but which could find a second life if only there were a means of directing it towards those in want.

This exists: For journals, books and apparatus, ICTP has established a coordination centre which will inform potential donors of the acceptability of their offer and the place to which the material concerned should be sent. If you have in physics and mathematics any textbooks you no longer use, volumes of journals that are taking up valuable space, or apparatus that is only gathering dust, write to:

Professor H.R. DALAFI

International Centre for Theoretical Physics POB 586

1-34100 Trieste

giving him details of what you are prepared to donate. He will then explain what should be done.

\section{International Physics}

\section{Impressions of the EPS Symposium on International Facilities for Physics Research}

As a follow-on to the Symposium on European Great Projects held in Rome from 26-27 March 1979, a Symposium on International Facilities for Physics Research was held from 21-23 March 1983 in Copenhagen and Ris $\emptyset$ prior to the meeting of the EPS Council. Sponsored also by the American Physical Society, the Risø National Laboratory (celebrating the 25th anniversary of its foundation through the initiative of Niels Bohr) and the Novo Foundation, and organised by a committee chaired by A.R. Mackintosh, the Symposium aimed at reviewing major facilities (existing and planned) for physics research throughout the world.

\section{Nuclear and Particle Physics}

At the opening session, contrasting pictures were painted of the diffuse situation in nuclear physics and the highly organised state of high energy physics where not only are the physicists mobilised on a regional basis, but even the major regions have complementary rather than competitive programmes. In the $1950 \mathrm{~s}$, much of the fundamental research in nuclear structure was made using Van de Graafs and small cyclotrons in university laboratories; in the ' 60 s tandem accelerators and isochronous cyclotrons came into operation and the inhigh resolution spectroscopy. By the '70s, with the upgrading of tandems and the growth in importance of heavy ion accelerators and electron linacs the centre of gravity had moved into specialised centres and, with the demand for machines of increased intensity and energy, collaboration at the international level is now becoming necessary. This trend is already in evidence. troduction of germanium detectors allowed
Machines that will be required before long include electron accelerators of a few $\mathrm{GeV}$ and high intensity (see Laget J.M. Europhysics News, May 1983), heavy ion accelerators capable of imparting up to 30 $\mathrm{GeV}$ per nucleon, as well as accelerators for the production of high intensity kaon and antiproton beams. Superconducting technology is becoming increasingly important, but the principles of acceleration remain traditional for the present, and novel methods will be required if continued progress is to be made. In comparison with high energy physics projects, the size of machines for nuclear physics research will remain modest, and a form of cooperation in which international use is made of a national facility, would seem to be more appropriate than another CERN.

CERN has now a multiplicity of interconnected accelerators and storage rings capable of a great diversity of operation. The most important facility is the $450 \mathrm{GeV}$ proton machine with an intensity of nearly $3 \times 10^{13}$ protons/pulse. It can be operated as a $270-270 \mathrm{GeV}$ proton-antiproton collider achieving luminosities of $5 \times 10^{28} \mathrm{~cm}^{-2}$ $\mathrm{S}^{-1}$ and the dramatic discoveries of the $\mathrm{W}$ and $Z^{\circ}$ particles provide triumphant proof of its research potential. The $p-p$ Intersecting Storage Rings with a centre of mass energy of $62 \mathrm{GeV}$ and luminosities of up to $1.4 \times 10^{32} \mathrm{~cm}^{-2} \mathrm{~s}^{-1}$ will be closed down at the end of this year to provide resources for the electron-positron ring LEP which will start as a $50-50 \mathrm{GeV}$ machine, then with superconducting RF cavities will be stretched to $80-80 \mathrm{GeV}$ and afterwards to $125-125 \mathrm{GeV}$. At the other end of the energy scale, a wide range of experiments is being conducted on low energy antiproton beams (momentum $0-600 \mathrm{MeV} / \mathrm{c}$ ) of very low momentum spread.
Table 1 - High Energy Physics Facilities Available in the USA

\begin{tabular}{|c|c|c|c|c|c|}
\hline Laboratory & & Device & Energy, GeV & $\begin{array}{l}\text { Intensity/ } \\
\text { Luminosity, } \\
\mathrm{cm}^{-2} \mathrm{~s}^{-1}\end{array}$ & Remarks \\
\hline BNL & AGS & p-synch. & 30 & $10^{13 / 2 \mathrm{~s}}$ & fixed target \\
\hline Fermilab & - & p-synch. & 400 & $2 \times 10^{13 / 10 s}$ & fixed target \\
\hline \multirow[t]{3}{*}{ SLAC } & - & e-linac & 33 & $10^{14} \mathrm{e} / \mathrm{s}$ & $\begin{array}{l}\text { fixed target } \\
\text { primarily e, } \gamma\end{array}$ \\
\hline & SPEAR & $\mathrm{e}^{+}-\mathrm{e}^{-}$collider & $3.5 /$ beam & $1.5 \times 10^{31}$ & ( 2 interaction regions) \\
\hline & PEP & $\mathrm{e}^{+}-\mathrm{e}^{-}$collider & $14.5 /$ beam & $2.2 \times 10^{31}$ & (6 interaction regions) \\
\hline \multirow[t]{2}{*}{ Cornell } & CESR & $\mathrm{e}^{+}-\mathrm{e}^{-}$collider & $5.2 /$ beam & $1.5 \times 10^{31}$ & ( 2 interaction regions) \\
\hline & & & & 500 (nb-day) $^{-1}$ & \\
\hline LANL & LAMPF & $\mathrm{p}$-linac & $0.8 \mathrm{GeV}$ & $10^{15} / \mathrm{s}$ & fixed target \\
\hline
\end{tabular}


At DESY which has a fully international experimental programme, two electronpositron storage rings are available: Doris now reaches $5.6 \mathrm{GeV}$ per beam with a luminosity of $10^{31} \mathrm{~cm}^{-2} \mathrm{~s}^{-1}$ and Petra is being up-graded to $22.5 \mathrm{GeV}$ per beam. In the planning stage is Hera, comprising a 30 $\mathrm{GeV}$ electron ring associated with a superconducting $820 \mathrm{GeV}$ proton ring, but a $30 \%$ participation in kind by countries other than the FRG has been indicated as a pre-requisite for the project to go ahead. It is by no means clear that this will be forthcoming.

In the USSR, UNK is designed as a twostage proton synchrotron working up to 3 $\mathrm{TeV}$ with superconducting magnets. Collider possibilities with antiprotrons are envisaged, and ultimately protons to give a 6 $\mathrm{TeV}$ centre of mass energy. The principal US facilities available are summarised in Table 1. SLAC is to build a $50-50 \mathrm{GeV}$ electron-positron ring to come into operation in 1986 and FNAL a $1-1 \mathrm{TeV}$ protonantiproton collider to come into operation in the same year.

Beyond these projects, it seems possible that an intercontinental approach would be needed, but the problems are vast and it was suggested that $20 \mathrm{TeV}$ was about the limit of present day techniques. Bearing in mind that nothing less than orders of magnitude increases in the energy of fixed target machines or factors of three or more in centre of mass energy for colliders are worth considering, it seems that in high energy physics too we are rapidly approaching the day when new technology will be needed.

\section{Synchrotron Radiation}

Straddling the accelerator requirements of nuclear and high energy physics is the broad need for synchrotron radiation facilities. Several facilities already exist in Europe, both originally conceived for high energy physics such as Doris at DESY, $\mathrm{ACO}$ and $\mathrm{DCl}$ at Orsay and Adone at Fracasti, and dedicated instruments such as the SRS in Daresbury and Bessy in Berlin. These give Europe a fairly adequate range of UV and VUV machines but to quote one speaker: there is "a frightening gap opening up between Europe and the USA in the $\mathrm{X}$-ray range" where we "desperately needed more intensity".

For these reasons the European Science Foundation has recommended the construction of a $5 \mathrm{GeV}$ storage ring fitted with undulators and wigglers, the characteristics of which can be adjusted without influencing the overall machine performance. The essential features of the "ESRF" have been worked out for some time and the proposal is now in the hands of an intergovernmental commitee, while a small project group continues with the elaboration of detailed design. Despite the pleas of the machine builders and potential users, it still
Table 2 - Storage Rings in Europe Emitting Synchrotron Radiation

\begin{tabular}{|c|c|c|c|c|}
\hline $\begin{array}{l}\text { Name } \\
\text { Location }\end{array}$ & $\begin{array}{l}\text { e } \\
\text { Energy. } \\
\text { GeV }\end{array}$ & $\begin{array}{l}\text { Current } \\
\mathrm{mA}\end{array}$ & $\begin{array}{l}\varepsilon c^{*}, \\
\mathrm{keV}\end{array}$ & $\begin{array}{l}\text { No of } \\
\text { Stations }\end{array}$ \\
\hline $\begin{array}{l}\text { ACO } \\
\text { Orsay }\end{array}$ & 0.54 & 150 & 0.31 & 15 \\
\hline $\begin{array}{l}\text { MAX } \\
\text { Lund }\end{array}$ & 0.55 & $(200)$ & 0.31 & $0(3)$ \\
\hline $\begin{array}{l}\text { BESSY } \\
\text { Berlin }\end{array}$ & 0.8 & $\begin{array}{l}200 \\
(500)\end{array}$ & 0.62 & 22 \\
\hline $\begin{array}{l}\text { Super } \\
\text { ACO_ } \\
\text { Orsay }\end{array}$ & 0.8 & & 0.65 & \\
\hline $\begin{array}{l}\text { ADONE } \\
\text { Frascati }\end{array}$ & 1.5 & $\leqslant 100$ & 1.5 & $4(5)$ \\
\hline $\begin{array}{l}\text { SR Da- } \\
\text { resbury }\end{array}$ & 2.0 & $\begin{array}{l}280 \\
(370) \\
\end{array}$ & 3.2 & $8(27)$ \\
\hline $\begin{array}{l}\mathrm{DCl} \\
\text { Orsay }\end{array}$ & 1.8 & 300 & 3.4 & 7 \\
\hline $\begin{array}{l}\text { DORIS } \\
\text { Hamburg }\end{array}$ & $\begin{array}{l}3.5 \\
-5.6\end{array}$ & $\begin{array}{c}\sim 200 \\
-30 \\
\end{array}$ & 22.9 & 25 \\
\hline $\begin{array}{l}\text { PETRA } \\
\text { Hamburg }\end{array}$ & 18 & 20 & 67.4 & 0 \\
\hline $\begin{array}{l}\text { PLAMIAIII } \\
\text { Moscow }\end{array}$ & 2.5 & 300 & 7.1 & (1985/86) \\
\hline ERSF? & 5.0 & 350 & $6-50$ & $20-40$ \\
\hline
\end{tabular}

\section{_. Under construction}

$\varepsilon c^{*}$ Median energy calculated in terms of the total radiated power

remains to be seen whether site selection will not pose the same intransigent problem as it did for JET. Characteristics of European synchrotron radiation facilities are given in Table 2.

\section{Neutron Beams}

Not so long ago, nuclear reactors were largely devoted to providing the basic data for the practical exploitation of nuclear fission. More recently, physicists from many disciplines - not least from solid state physics, have been the principal users of the very high flux reactors notably those that have come into operation since the late sixties at the Brookhaven and Oak Ridge National Laboratories in the USA and the ILL in Grenoble where fluxes in excess of $10^{15} \mathrm{n} / \mathrm{cm}^{2} \mathrm{~s}$ are available. Now it would seem that neutron beam research is at something of a bifurcation as the demand in some sectors for higher intensities is leading to the application of pulsed sources because of limitations on the heat dissipation in the reactors.

This is the reason behind the IBR pulsed beam reactor in the USSR and the use of electron accelerators as neutron generators. More efficient though are protonactivated spallation sources. The $800 \mathrm{MeV}$, $200 \mu \mathrm{A}$ Spallation Neutron Source at the Rutherford Appleton Laboratory is due to come into operation in 1986 but could be preceded by the source at SIN, which will reach a current of $2 \mathrm{~mA}$ if appropriate funding is forthcoming. The proposed SNG in the FRG is aiming at a primary beam of $1100 \mathrm{MeV}$ at $5 \mathrm{~mA}$ over $500 \mu$ s which could be compressed to a pulse of $0.7 \mu$ s yielding a peak neutron intensity of $1.5 \times 10^{17}$ $\mathrm{n} / \mathrm{cm}^{2} \mathrm{~s}$, a most potent research tool.

With ILL and national research reactors looking after the cold end of the spectrum and the spallation sources providing high intensity beams at shorter wavelengths, Europe seems to be well provided for over the next few years (a "negative gap" compared with the USA was even suggested) but a more effective access to the available facilities needs to be worked out as some are under- while others are over-subscribed.

\section{Fusion}

European research in controlled fusion is primarily concentrated on the tokamak system with the JET experiment at Culham in the UK as the centre piece of the western European effort (see Gibson A., Europhysics News, April 1983). This project which is the most ambitious of its kind in the world is running commendably to schedule; the first discharge was achieved on 25 June and the current raised to $100 \mathrm{kA}$ the following day. In the USA, the equivalent experiment, the TFTR, came up to its current limit (with the presently available power supplies) of $1 \mathrm{MA}$ a few days later. These machines have now a long programme of research ahead of them and it will be a few years before one can forecast whether the break-even conditions of temperature, density and confinement time can be met - or even whether the results justify injecting tritium and making the systems radioactive. Characteristics of the major non-European tokamaks are given in Table 3.

More attention is being paid in the USA to open-ended systems such as the tandem mirror concept (D.E. Baldwin, EN, Aug./ Sept. 1981), but interest in Europe in stellarators (Wobig H., EN, Aug./Sept. 1982) has revived and a number of significant experimental approaches are being tested or are in course of construction. Decisions on the Reversed Field Pinch Experiment planned for Padova which has been agreed in principle for many months are expected in the Autumn. Research in western Europe is effectively coordinated from the European Communities and manages to include the work of smaller laboratories which would have little raison d'être on their own. On the international plane, it would seem that scientific communication is at a high level and the NET (Next European Torus) assessment is being conducted as a contribution to the intercontinental study INTOR. Fusion, nevertheless, has still some way to go to arrive at the level of open international collaboration that is current in high energy physics.

\section{Astrophysics}

These are golden years in astronomy as satellites and new technology open up wavelengths and distant objects that have 
Table 3 - Major Non-European Tokamaks

\begin{tabular}{llllll}
\hline Device & $\begin{array}{l}\text { Loca- } \\
\text { tion }\end{array}$ & $\begin{array}{l}\text { Ra- } \\
\text { dius, } \\
\mathrm{m}\end{array}$ & $\begin{array}{l}\text { Minor } \\
\text { radius, } \\
\mathrm{m}\end{array}$ & $\begin{array}{l}\text { Field, } \\
\mathrm{T}\end{array}$ & $\begin{array}{l}\text { Cur- } \\
\text { rent, } \\
\text { MA }\end{array}$ \\
\hline DIII & US & 1.43 & 0.44 & 2.6 & 1.5 \\
& & & 1.40 & & \\
PLT & US & 1.30 & 0.45 & 3.5 & 0.6 \\
TFTR & US & 2.45 & 0.85 & 5.2 & 2.5 \\
JT-60 & Japan & 3.0 & 1.0 & 5.0 & 3.0 \\
T-15 & USSR & 2.4 & 0.7 & 3.5 & 1.4 \\
\hline
\end{tabular}

been obscured from terrestrial eyes until now. The window in the atmosphere is small and for the first time the broad expanse of the electromagnetic spectrum has become accessible; astronomers now can choose the wavelength appropriate to the problem under study rather than being constrained to formulate their research around the wavelengths available. In the sub-mm and infrared, the most recent instrument is the IR cryogenic Astronomical Satellite which is a collaboration between the NL, US and UK. The data being received are superb and a whole sky survey will be undertaken. Follow-up projects are ESA's European telescope ISO and a separate project of the FRG; NASA is building a facility to be serviced by the shuttle and both ESA and NASA are planning ambient temperature telesopes of $7 \mathrm{~m}$ aperture and specialised instruments for investigating anomalies in the cosmic background and for studies at very high resolution. In the far and extreme UV there is the Extreme UV Explorer and the Far Uv Spectroscopic Explorer. At $\mathrm{X}$-ray wavelengths the first results have come in from the UHURU mission, the Einstein telescope has been a great succes, ESA's EXOSAT has recently been put into orbit and other European missions that are planned include ROSAT of the FRG.

In the near IR, optical and UV the main instrument will be the Space Telescope due to be launched in 1985 (superceding the ESA/NASA IUT which has been operating for some time). The $2.4 \mathrm{~m} \mathrm{ST}$ is a joint NASA-ESA project with ESA contributing $15 \%$. To evaluate programmes and assign viewing time, a special science institute which includes Europeans has been set up in Baltimore. Data collected during a particular series of observations will be at the sole disposal of the observer for one year, after which it must be archived. The quantity of data collected will be enormous and a European Coordinating Facility is being set up at ESO in Garching to simplify access from this side of the Atlantic. Concern was expressed that with such a facility the observer was dependent on other people's instrumentation even if, as expected, most observers will go to Baltimore during their data taking. The system of costing has also still to be finalised but this aspect is not so novel. The ST clearly will be a big experiment in organization and communication as well as in astronomy.
Ground- based astronomy is, at the same time, far from becoming obsolescent as the telesopes are so much cheaper to build and complex detectors so much easier to operate. A salutary reflexion is that the cost of replacing all the ground-based optical telescopes ever built would still be less than the cost of the ST. Improvements in sensitivity over recent years have come about not only from the greater effective lightgathering power resulting from more refined optics and pointing control with the modern telescopes of around $3^{1 / 2} \mathrm{~m}$ aperture, but also from higher detector quantum efficiencies which now achieve some $50-60 \%$. This has justified the planning of a new range of very large telescopes with apertures of the order of $16 \mathrm{~m}$.

These would not be practicable without a new approach to telescope building. New control technologies permit the diameter/thickness ratio of the primary mirror to be increased from six, as at present, to between 15 and 50 , deformations being compensated through a dynamic support system. New instrument mounting, compact structures and small buildings will also contribute to cost reductions. The ESO $3.5 \mathrm{~m}$ New Technology Telescope due to be completed in 1986 which will serve as a prototype for a future VLT will cost less than $\$ 10 \mathrm{M}$. Table 4 shows the large optical telescopes under design. Despite this richness, however, Europe is not too well provided with medium-sized telescopes which can do much useful work on their own and also allow more efficient use to be made of the large aperture instruments.

In much of the radio spectrum, interferometry is the dominant technique providing angular resolution at the arc-s level. Very Long Base-line Interferometry is an ideal technique for international collaboration and has already proved its value. Currently a VLBI array making use of mostly existing telescopes is planned in Europe while in the USA and Canada, fully dedicated VLBI arrays are under study. At $\mathrm{mm}$ wavelengths however, large single dish telescopes, as at IRAM, may provide acceptable angular resolution for certain observations.

Table 4 - Large Future Optical Telescopes under Design

\begin{tabular}{|c|c|c|}
\hline Organization & $\begin{array}{l}\text { Diameter, } \\
\mathrm{m}\end{array}$ & Characteristics \\
\hline U. of Texas & 7.6 & $\begin{array}{l}\text { Very thin single } \\
\text { mirror }\end{array}$ \\
\hline $\begin{array}{l}\text { U. of } \\
\text { California }\end{array}$ & 10 & $\begin{array}{l}\text { Segmented mirror } \\
\text { positioned with a } \\
\text { laser system }\end{array}$ \\
\hline $\begin{array}{l}\text { Kitt Peak } \\
\text { Nat. Obs }\end{array}$ & 15 & $\begin{array}{l}\text { Segmented mirror } \\
\text { or Super MMT } \\
\text { (Multi-Mirror } \\
\text { Telescope) with } \\
\text { independent mir- } \\
\text { rors }\end{array}$ \\
\hline ESO & 16 & $\begin{array}{l}\text { Array of } 4 \text { in- } \\
\text { dependent } 8-m \\
\text { telescopes }\end{array}$ \\
\hline UK & 17 & Super MMT \\
\hline
\end{tabular}

\section{Discussion}

Physics is clearly not short of big projects and they are becoming steadily more ambitious. This raises immediately the question of priorities, but whereas within a given field, mechanisms have been and are being developed for defining these, particularly when an international centre already exists such as CERN or ESO, there seems at present to be no rational way of choosing between the competing demands of different fields. History and the drive of an effective champion tend to be the determining factors. It was suggested that given the multidimensional nature of the problem (including social and political factors) the primary task of physicists was not to concern themselves with field selection so much, but concentrate instead on the development of resources, notably talent, and to see that lines of activity were consistent and that commitments were fulfilled. Particular difficulties arise in connexion with space exploration where science may be subsidiary to other objectives and the astrophysics community needs to be both coherent and realistic to gain the maximum advantage from the possibilities.

International cooperation is needed the moment a project becomes too big or involves skills over and above those available in a single country. In the USA, the economic limit was suggested to be around 1 G\$ but this is clearly beyond what most countries can afford. In European terms, an order of magnitude less would seem more relevant. Collaboration between countries is not easy and it is facile to blame the politicians when the rivalry between different scientific groups can be just as selfdestructive. Problems become acute when practical applications might follow immediately, but for much of physics this is not the case, although it will arise if fusion develops as expected. No single formula for the structure of an international project can be recommended: different stengths and interests have to be accommodated and the CERN model, although extremely successful, is no universal panacea. Preference was rather given to the idea of one dominant partner taking the lead, although this is not the principle behind either CERN or JET.

Fears were expressed that the progressive increase in size and institutionalisation of research facilities would alienate the universities, which would be a threat to our whole educational system. There is scant evidence, however, that this would happen and it is clear, for example, that the strength of high energy physics in the European universities depends decisively on CERN's existence. What is required is a change in attitude and a progressive adaptation to new methods of working.

More real is the general problem of the smaller countries and there is wide-spread concern that scientists from these will be 
excluded from frontier research. A wise choice of topics can alleviate the situation, but the key lies in the mobility of the gifted people and in their having access to the big installations. The initiative though must come from the smaller countries - they are unlikely to meet a negative response if they make the effort.

An epitome of the Risø Symposium, including inter alia extended abstracts of the invited lectures and a summary of the discussions, is being published by the Ris $\emptyset$ National Laboratory and was due to appear early in September. Copies may be obtained from the EPS Secretariat, price Sw.Fr. 25. - .

\section{Europhysics Letters}

Following the decision taken by Council to invite national societies to participate in the launching of the EPS Europhysics Letters project, a wide consultation has been taking place in Europe. Already a number of national societies have indicated their interest in the project and their wish to be involved in the preparatory phases. It is, however, too early to make any definite statements on the status of the project but between now and the end of the year it is hoped that a definite framework can be established so that Council can be presented in March with a firm proposal.

\section{Europhysics Conference Abstracts}

The present Series of Europhysics Conference Abstracts - Series 7 - comprises eight volumes covering all the EPS (Divisional) Organized Conferences which take place in 1983 and for which abstracts are published. Subscription price for a complete set is Sw.Frs. 290. - for new subscribers and Sw.Frs. 250. - for regular subscribers.

The EPS Secretariat still has stocks of previous Series and is able to supply as an alternative to full sets individual volumes at a price which can be obtained on application. Subscriptions or enquiries concerning the Series should be addressed to the EPS Secretariat in Geneva.

EPS Divisions, Sections and Group

Astronomy and Astrophysics Division Solar Physics Section

Atomic and Molecular Physics Division

Atomic Spectroscopy Section

Atomic Spectros

Electronic and Atomic Collisions Molecular Physics

Computational Physics Group

Condensed Matter Division

Low Temperature Physics Section

Macromolecular Physics

Magnetism

Metal Physics

Metal Physics

Semiconductors and Insu
Surfaces and Interfaces

High Energy \& Particle Physics Division

Nuclear Physics Division

Optics Division

Plasma Physics Division

Quantum Electronics Division

\section{CMD ELECTIONS}

\section{Call for Nominations for the Sections of the Condensed Matter Division}

Elections to the Committees responsible for the Sections of the Condensed Matter Division will be held in November/December by mail.

Below is a provisional list of candidates prepared by the Chairman of the Division in consultation with the present Committee Chairmen. Individual Ordinary Members who are Section members and National Societies, Category $4 \mathrm{~b}$ ), are invited to make additional nominations. Those made by I.O.M.s should be supported by at least six members.

The Committees consists of six full members, elected for a term of three years, plus up to six co-opted members. The Sections then elect their own Chairmen and these serve on the Board of the Division. The maximum continuous period over which a Committee member may serve is six years.

In the lists that follow, the names of the Committee members elected at the last elections in 1980/81 are marked with an asterisk.
Low Temperature Section

Y. Bruynseraede, Leuven

*) G. Deutscher, Tel-Aviv

I. Kirschner, Budapest

${ }^{*}$ ) M. Krusius, Turku

F. Pobell, Julich

H. Postma, Delft

F.B. Rasmussen, Copenhagen

L. Rinderer, Lausanne

*) D. Thoulouze, Grenoble

*) W.F. Vinen, Birmingham

Macromolecular Section

F.J. Baltà-Calleja, Madrid

*) G. Bodor, Budapest

-) A. Keller, Bristol

H.G. Kilian, UIm

J.P. Mercier, Louvain-la-Neuve

*) L. Monnerie, Paris

K.-H. Roth, Leipzig

\section{Magnetism Section}

*) L.J. de Jongh, Leiden

*) R. Elliott, Oxford

J. Kaczer, Prague

*) G.M. Kalvius, Munich

E. Karlsson, Uppsala

S. Methfessel, Bochum
Metals Section

D. Bacon, Liverpool

*) D. Buschow, Eindhoven

R. Cahn, Paris

*) O. Fischer, Geneva

*) J.P. Gaspard, Liege

E. Lüscher, Garching/Munich

Semiconductors and Insulators Section

J.W. Allen, St. Andrews

*) D. Bäuerle, Linz

*) F. Beleznay, Erlangen

*) R. Blinc, Ljubljana

*) H. Grimmeiss, Lund

*) G. Harbeke, Zurich

G.J. Rees, Towcester

Surfaces and Interfaces Section

*) G. Benedek, Milan

A. Bradshaw, Berlin-West

*) B.I. Lundqvist, Göteborg

F. Saris, Amsterdam

H.-C. Siegmann, Zurich

*) R.F. Willis, Cambridge

K.-F. Wojciechowski, Wroclaw
F. Koch, Munich

Nominations should arrive at the EPS Secretariat by 11 November 1983 at the latest.

\section{Proceedings of the 3rd CMD General Conference}

The Proceedings of the 3rd General Conference of the EPS Condensed Matter Division, Lausanne 28-30 March 1983, have been published as a triple issue of Helvetica Physica Acta, $882 \mathrm{pp}$. A very limited number of copies are available for Individual Ordinary Members for personal use at the special price of Sw. Frs. 60.-. Orders accompanied by a cheque drawn on a Swiss Bank to the EPS Secretariat, POB 69, CH-1213 Petit-Lancy 2.
Europhysics News is the official journal of the European Physical Society which comprises 29 National Societies, Academies and Groups, over 3000 Individual Members and 64 Associate Members. Governing bodies of EPS are the General Meeting, Council and an elected Executive Committee responsible for detailed policy. EPS promotes the collaboration of physicists throughout Europe, organising and harmonising conferences, and promotes international exchanges in physics including participation in research and teaching activities abroad and attendance at schools. EPS publishes in addition to EN, Europhysics Conference Abstracts, E. Ed. News and, in collaboration with The Institute of Physics (UK), the European Journal of Physics. Individual Members receive EN free of charge (price to institutions: Sw.Fr. 82. - /a), rebates on the price of many publications and on conference fees. Annual fee for Individual Members from one of the EPS member societies for 1983 is: Sw.Fr. 40,-; independent members: Sw.Fr. 120.-; APS members: Sw.Fr. 50. - = \$25. -

\section{Editor: E.N. Shaw}

Meetings Compilation: W.S. Newman

Editorial Board:

K. Appert, A. Baratoff, G.J. Béné,

G.R. Macleod. A. Maeder, J. Muller

Editorial and Advertising Office at the EPS Secretariat.

Address: EUROPEAN PHYSICAL SOCIETY P. O. Box 69 . CH-1213 Petit-Lancy 2 Switzerland

Telephone: Geneva (22) 931130

Telex: $\mathbf{4 2 3} \mathbf{4 5 5}$ dema ch

Cables: europhys genève

Printed by: Pfirter frères SA CH-1213 Petit-Lancy/Switzerland 